\title{
Memória e representação da figura masculina em canções tradicionalistas
}

\author{
MEMORY AND REPRESENTATION OF THE MALE FIGURE IN GAÚCHA TRADITIONALIST
}

\section{Ana Paula Teixeira Porto}

Universidade Regional Integrada do Alto Uruguai e das Missões - URI - Frederico Westphalen - Rio Grande do Sul - Brasil

Resumo: Reconhecer o imaginário cultural rio-grandense representado em obras de grande repercussão junto ao público é uma das motivações desta pesquisa, cujo objetivo é discorrer sobre como se dá a representação da figura masculina, a partir da identificação de seu perfil, valores e ideais, em canções tradicionalistas gaúchas, compostas do final do século $\mathrm{XX}$ ao $\mathrm{XXI}$. Toma-se como objetos de análise canções que, conforme apontam as referências bibliográficas, são consideradas populares e largamente reconhecidas pelo público ouvinte no contexto sulino, construindo-se produtos da cultura de massa. As canções selecionadas no corpus deste trabalho são selecionadas a partir da obediência aos seguintes critérios: compostas ou gravadas por José Cláudio Machado, um dos artistas mais populares do tradicionalismo gaúcho; referência à figura masculina nas letras; canções gravadas por grupos ou intérpretes que obtiveram destaque junto ao público. A pesquisa de caráter bibliográfico limita-se à análise das letras, não destacando a melodia e os arranjos musicais como ponto de reflexão. Na composição das letras dessas canções, a representação da figura masculina parece ser um elemento importante de manutenção de figura masculina ligada ao campo assim como de conservação de valores e pressupostos culturais de gênero e de estereótipos masculinos cultuados desde o século XIX no Rio Grande do Sul, de forma a manter certos traços caracterizadores da valentia, da superioridade e da virilidade do homem gaúcho. Nessa perspectiva, entende-se que a construção da memória da figura masculina está atrelada a uma visão conservadora e patriarcal, o que implica a revalorização do passado cultural.

Palavras-chave: Memória. Figura masculina. Canção.

\begin{abstract}
To recognize the Rio-grandense cultural imaginary represented in works with great repercussion among the public is one of the motivations of this research, whose purpose is to deal with one main problem: how is the male figure depicted departing from the identification of his profile, values, and ideals, in regional traditionalist songs written by the end of the $\mathrm{XX}^{\text {th }}$ century to the $\mathrm{XXI}{ }^{\mathrm{st}}$ ? The corpus of analysis is composed by songs that, as the bibliographical references point out, are considered popular and widely recognized by the listening public in the southern Brazilian context, building up products of mass culture. The songs were selected according to the following criteria: written or recorded by José Cláudio Machado, one of the most popular artists of the gaúcho traditionalism; reference to the male figure in the lyrics; songs recorded by groups or interpreters who achieved distinction among the public. The bibliographical research is circumscribed to the analysis of the lyrics, emphasizing neither the melody nor the musical arrangements as a point of reflection. In the composition of such lyrics, the representation of male figure seems to be an important part of the preservation of male figure linked to the rural area along with the preservation of values and cultural assumptions of genre and male stereotypes worshiped in Rio Grande do Sul since the XIX ${ }^{\text {th }}$ in order to maintain certain features of bravery, superiority, and virility of the gaúcho man. In this perspective, the construction of male figure memory is linked to a conservative and patriarchal vision, which entails the upgrading of the cultural past.
\end{abstract}

Keywords: Metaphor. Memory. Male figure. Song. 


\section{Introdução}

Compreender objetos artísticos, como os da música, como elementos representativos da cultura é um caminho profícuo para entender que "a cultura é um campo de produção de significados no qual os diferentes grupos sociais, situados em posições diferenciais de poder, lutam pela imposição de seus significados à sociedade mais ampla" (SILVA, 2000, p. 133-134). Partindo-se dessas premissas, a proposta deste estudo é tecer algumas considerações sobre letras de músicas populares no universo cultural do tradicionalismo do Rio Grande do Sul. Refletir sobre a representação do homem gaúcho em letras de canções é o ponto de partida deste artigo, que toma como objeto de análise letras de canções tradicionalistas populares e de grande repercussão, compostas e/ou interpretadas por José Cláudio Machado, um dos mais reconhecidos artistas da cultura tradicionalista do Rio Grande do Sul.

José Cláudio Machado, natural de Tapes, teve sua trajetória musical encerrada em 2011 depois de mais de 40 anos dedicados à música. Foi compositor reconhecido pela crítica e premiado ao vencer a Califórnia da Canção Nativa de 1972 com a canção "Pedro Guará". Alcançou sucesso com as canções "Lástima", "Batendo Casco", "Defumando Ausências" e "Milonga abaixo de mau tempo", as quais impulsionaram regravações de vários artistas gaúchos, como Walther Moraes, Luiz Marenco e o grupo Os Serranos. José Cláudio Machado gravou mais de 15 álbuns, além de ter feito participações especiais em projetos de outros artistas. Seu último CD é Os Melhores Sucessos de José Claudio Machado, de 2007. Quatro anos mais tarde, sua morte dá fim a uma carreira de sucesso.

Apesar de sua longa trajetória artística e do sucesso conquistado junto ao público gaúcho, poucas são as referências acadêmicas que se dispõem a discorrer sobre a produção de José Cláudio Machado, uma produção musical composta por um acervo de canções autorais ou daquelas nas quais apenas empresta sua voz de intérprete. O sucesso dessas canções é notório, mas nem sempre vem acompanho de uma leitura mais atenta aos significados, aos valores que elas trazem nos versos carregados de linguagem regionalista e personagens que, de certa forma, cristalizam os sujeitos a que remetem, no caso os homens e mulheres gaúchos.

Interessa nesse estudo uma leitura específica: a de como letras de canções imortalizadas por José Cláudio Machado constroem a figura do homem gaúcho. Que imagens são estas? Que valores acentuam? Que perfil delineiam? Questões como essas norteiam este trabalho que parte de uma exposição sobre o universo tradicionalista do qual fazem parte as letras de canções analisadas.

\section{Tradicionalismo no Rio Grande do Sul}

Para reconhecer o cenário musical de que fez parte José Cláudio Machado, é preciso contextualizar a acepção de tradicionalismo, que se distingue da ideia de tradição, cuja definição geral está relacionada, em termos mais gerais, ao "produto do passado que continua a ser aceito e atuante no presente", constituindo um "conjunto de práticas e valores enraizado nos costumes de uma sociedade", conforme explicam Silva e Silva (2006, p. 1). Em relação aos conceitos de tradição e tradicionalismo, é pertinente observar que:

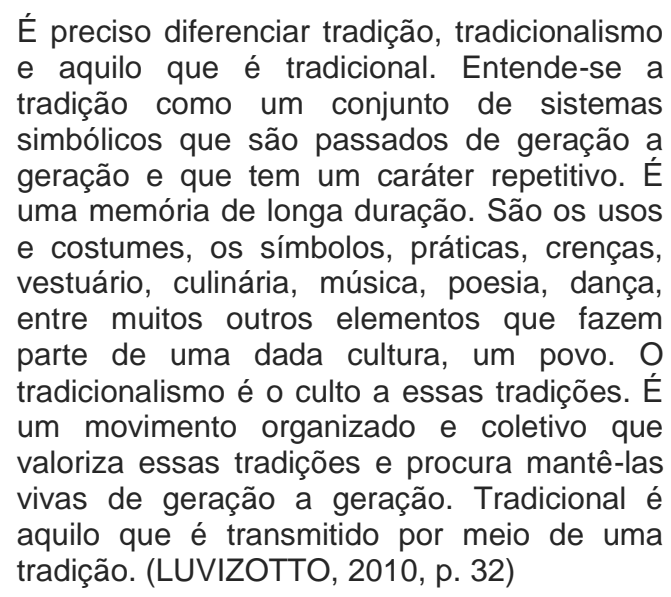

Ainda sobre a discussão acerca do tradicionalismo, pode-se apontar que tradicionalismo é o movimento popular que visa a auxiliar o Estado na consecução do bem coletivo, através de "ações que o povo pratica (mesmo que não se aperceba de tal 
finalidade) com o fim de reforçar o núcleo de sua cultura: graças ao que a sociedade adquire maior tranquilidade na vida em comum (LESSA, s.d.)". Lessa (s.d.) discorre sobre o conceito, defendendo a ideia de que o tradicionalismo ilustra práticas de uma cultura que emana do povo.

No Rio Grande do Sul, o tradicionalismo se prolifera na primeira metade do século $X X$, especialmente com a "criação do 35 CTG, o primeiro Centro de Tradições Gaúchas (não se levando em conta a existência de centros pioneiros do fim do século passado e início deste) por um grupo de estudantes secundários de Porto Alegre" (OLIVEN, 1985, p. 79). É vivenciado em CTGs - Centros de Tradição Gaúcha -, os quais chegam a 1700 unidades somente no RS, além de outros em outros estados brasileiros e em países europeus e nos Estados Unidos, fundados por brasileiros que lá fixaram residência.

Esse processo de criação e implementação de CTGs tem suas origens na atuação de três referências da cultura tradicionalista. Segundo a perspectiva de Luvizotto (2010), o Rio Grande do Sul tem guardiões da memória tradicionalista: Paixão Côrtes, Barbosa Lessa e Glaucus Saraiva, considerados, respectivamente, idealizador, intelectual e organizador do movimento (LUVIZOTTO, 2010, p. 31). Ao trabalho desses tradicionalistas deve-se, além de pesquisa sobre cultura, dança e folclore gaúchos, a consolidação inicial dos CTGs. Ainda em relação ao conceito de tradicionalismo, Konflanz (2013, p. 22) explica que:

\begin{abstract}
O "Tradicionalismo Gaúcho" pode ser descrito como um Movimento cultural originado no Rio Grande do Sul que expressa o apego de parte da população do estado pelas coisas do campo e por episódios históricos mitificados da região. Além disso, tem como representação simbólica os antigos gauches um tipo social do pampa (que também serve como representação mítica dos habitantes do estado) - sendo por isso, também essa manifestação chamada de "gauchismo". (KONFLANZ, 2013, p. 22).
\end{abstract}

Para Konflanz (2013, p. 24), o tradicionalismo está relacionado à construção de um imaginário social que pode ser compreendido como uma

representação parcial do processo histórico do Rio Grande do Sul, a qual está baseada em uma perspectiva de mitificação, conferindo a essa representação um caráter coletivo. Essa pode estar associada à imagem idealizada do homem gaúcho, tão comumente construída em textos literários e canções regionalistas do Estado. Segundo o autor:

\begin{abstract}
Se tratando do imaginário social, o Tradicionalismo Gaúcho representa a identidade coletiva do Rio Grande do Sul. Possui a autoridade representativa da identidade cultural do estado. Por influência do Movimento, o tipo social símbolo do tradicionalismo, o gaúcho, se tornou o nome gentílico dos habitantes da região. (KONFLANZ, 2013, p. 24),
\end{abstract}

Se o tradicionalismo é uma constante no imaginário cultural do Rio Grande do Sul, colaborando para determinadas representações sociais e culturais, certamente as canções tradicionalistas, como gêneros atrelados a uma cultura que atinge a massa e que visa a dialogar com esse tradicionalismo, também são representativas dessa construção. Como estabelecem essa relação e que valores disseminam é a proposta de reflexão a seguir.

\section{Tradicionalismo e as canções de José Cláudio Machado}

Quando se pensa em canções tradicionalistas gaúchas, restringindo-se as reflexões às letras e excluindo a construção melódico-musical e arranjos sonoros de cada uma, logo algumas tendências são identificadas. Uma delas está atrelada à associação entre homem e animal numa relação de afeto e/ou de trabalho e serventia. Não raro se encontram cavalos e cães como companheiros da figura masculina. Nesse sentido, observa-se ainda que o homem gaúcho é sempre associado a algum animal que remete à ideia de virilidade, como o cavalo no campo da psicanálise, "está associado ao psiquismo inconsciente, nãohumano, está ligado aos relógios naturais e à impetuosidade dos desejos" (DICIONÁRIO DOS SíMBOLOS, s.d.). A relação do homem com o cavalo, sendo este um companheiro inseparável para lides 
campeiras, pode ser associada à clarividência, pois, "se o cavalo simboliza os componentes animais, inconscientes e irracionais do homem, também esclarece a razão pela intuição. O cavalo e o cavaleiro estão intimamente unidos" (DICIONÁRIO DOS síMBOLOS, s.d.).

Em "São as armas que conheço", canção composta por José Cláudio Machado, essa relação do homem com o animal é apresentada de modo a salientar o cavalo como um objeto que acompanha diretamente a vida do homem do campo, como se enfatiza nos seguintes versos: "Um lombilho, um baixeiro, cincha, peiteira e rabicho/ Buçal, cabresto e maneia e uma espora garroneira/ Mango, rédea e bocal são as armas que conheço/ Pra fazer um cavalo manso quando me entregam um bagual". $\mathrm{Na}$ letra de "Gaúcho", também composta por José Cláudio Machado, está explícita essa relação: "No lombo do seu cavalo se espalhou por este chão/ $E$ cruzou sangue com sangue fez raça neste rincão/ $\mathrm{E} o$ centauro será visto por mais que você ande/ Cruzando lanças e raças na defesa do Rio". Em ambas as letras, o aporte do cavalo dá ao homem maior sustentação, força e coragem, o que contribui para torna a figura humana idealizada.

Essa associação da figura masculina ao cavalo ainda permite reconhecer, nas entrelinhas, que o imaginário cultural assim construído remete a uma oposição masculino/feminino. Se o homem é viril, forte e tem consigo a clarividência, o que lhe dá uma posição de destaque, há um outro polo que não é forte nem tem esse poder de ver e antever. Esse polo associa-se à mulher, relacionada à imagem daquela que espera, que é submissa à vontade do seu marido (SOARES; SOARES, 2006).

Além dessa correlação homem/cavalo, é constante a representação da trajetória dos personagens das canções em cenários rurais, do campo, da fazenda, onde o homem parece estar mais livre e ter possibilidade de externar sua coragem e bravura. Nos versos a seguir de "São as armas que conheço", a vida no campo é descrita de forma clara: vive o homem rodeado de bois que lhe ajudam na construção do sustento, advindo do plantio na "terra bruta" que traz o "trigo pro pão", como se conclui nestas estrofes:

Ou uma junta de boi mansos, um arado, pula-toco Cangas, brochas, tamoeiros, uma regeira um cambão

Machado, enxada e facão são as armas que conheço

Pra fazer a terra bruta me dar o trigo pro pão

Esteios, rimas, baldrames, travessas e cachorretes

Caibros e pontaletes, gaipa, taquara e cipó

Cupim, leiva em Santa Fé são as armas que conheço

Pra fazer meu próprio rancho e deixar de viver só

$\mathrm{Na}$ letra de "Milonga abaixo do mau tempo", composta por Mauro Morais e popularizada na voz de José Cláudio Machado, tem-se a voz de um eu-lírico que expressa a vida do campo e o trabalho com a "gadaria toda/ Penando a dor do mango com o focinho n'água". Novamente, vê-se a repetição de uma imagem que se torna emblemática da figura masculina: vida no campo, o trabalho com o gado, o cavalo como companheiro de labuta.

A vida campesina do homem gaúcho também serve para emoldurar a imagem desse homem a de um sujeito livre, que gosta de liberdade e age em função dela. Nestes versos de "Gaúcho" (com composição de José Cláudio Machado), o caráter despachado do personagem é ressaltado: "Nos quatro cantos da terra gaúcha existe um centauro do pago/ Rude, guapo e despachado na maneia dos afagos/ Saidor e mui ginete sovador de corda e potros / Peleou com garras e lanças mas fez pátria nos encontros". Tal coanterização pode ser associada ao conceito de gaúcho. Segundo Love (1975), a palavra gaúcho, o homem livre dos campos, foi aplicada inicialmente para definir um tipo humano arredio, o nômade do pampa, muitas vezes um desertor desobediente da lei e da ordem, que cavalgava sem rumo numa área vastíssima sempre atrás de gado amansado ou xucro e de cavalos (apud LUVIZOTTO, 2010).

De acordo com Oliven (2006, p. 66), essa figura do homem livre dos pampas e domador de cavalos iniciou um processo de criação da identidade do gaúcho. O termo passa a ser usado para exaltar e 
definir um tipo de sujeito que possui um passado de honras e glórias e que "formou homens à imagem de um tipo ideal, criado em meio à liberdade do campo, montado em seu cavalo, desbravando a natureza, protegendo as fronteiras, respeitando o inimigo e lutando pela honra e pela justiça" (apud LUVIZOTTO, 2010). Essa perspectiva também transparece quando o eu-lírico de "Gaúcho" concluir que, na labuta com seu cavalo, o homem gaúcho defende sua nação riograndense mesmo que para isso seja necessária uma luta com sangue:

\author{
No lombo do seu cavalo se espalhou por este \\ chão \\ E cruzou sangue com sangue fez raça neste \\ rincão \\ E o centauro será visto por mais que você ande \\ Cruzando lanças e raças na defesa do Rio \\ Grande
}

\section{Gastou espadas e potros peleou de adaga e garrucha \\ O que seria deste pago sem essa raça gaúcha}

Se por um lado há a representação de um gaúcho livre, por outro também se tem a de que ele é um sujeito que crê, que acredita em entidades divinas, pois, como destacado em "Milonga abaixo do mau tempo", "O campo alagado nos obriga à reza" e "Dei falta da santinha limpando os pesuelos/ E do terço de tento nas preces sinuelas/ Logo em seguidinha é semana santa/ Vou cego pra barranca e só depois vou vê-la". Essa religiosidade dada ao homem também é um elemento que favorece a construção de sua imagem idealizada, uma vez que, tendo essa espiritualidade religiosa como algo relacionado ao bem e à harmonia, os traços positivos da figura masculina se enaltecem.

Além dessa caracterização, percebe-se um desejo masculino em ter ao seu lado a companhia de alguém, o que remete a uma perspectiva tradicional de união, como se vê nos versos de "Gaúcho": "Gaúcho forte/ Pra querência voltarei/ No potreiro dos teus olhos/ Nunca mais me apartarei". Ainda se nota que a figura masculina apresenta o sonho por amor de uma mulher, o que se configura como um modelo patriarcal de união, perpetuando uma referência de família tradicional.
O gaúcho também pode ser pensado como uma figura emblemática, pretendendo sintetizar e expressar uma determinada imagem dos habitantes da região, transmitindo "ideias e valores sobre como seriam (ou deveriam ser) os gaúchos. [...] A figura do gaúcho como representativa de uma identidade regional é elaborada a partir de uma busca pelo que seria denominador comum, procurando 0 que diferencia, perdura". (MACIEL, 2000, p. 79 apud LUVIZOTTO, 2010)

Ao se analisar as letras das canções que compõem o corpus deste trabalho, pode-se identificar quatro tendências centrais na representação da figura masculina: homem ligado ao campo; homem religioso, forte, corajoso e viril; homem familiarizado com animais; homem ligado à família tradicional. Essas tendências aludem algumas observações. A primeira está relacionada à ideia de que todos os atributos referenciados à figura masculina convergem para uma visão idealizada: não se encontram nesses versos referências negativas ou fragilidades da figura masculina. Pelo contrário, a perspectiva sempre é a de enaltecê-la.

A ligação do homem com o cavalo, caracterizado não apenas como meio de transporte, mas também como companheiro numa relação de afetividade entre homem e animal, pode estar atrelada à memória histórica de construção da identidade regional na medida que esse contexto remete aos índios, uma das etnias que formaram o Rio Grande do Sul. Para Oliven (1992), o apego do homem gaúcho ao cavalo está associado ao povo indígena, que contribuiu na formação étnica do Estado, juntamente com portugueses, negros, italianos, espanhóis e alemães. Segundo o autor,

Contribui para isso, o fato de o índio ter sido reduzido a um número mínimo e portanto ter pouco contato com os brancos, de ele não ter sido escravizado na mesma proporção que o negro, de ele estar associado a uma imagem de bravura e altivez e o fato de os charruas e minuanos, grupos que não existem mais e que habitavam a região da Campanha no sudoeste do Rio Grande do Sul quando os ibéricos chegaram, terem sido guerreiros e a partir da introdução do cavalo hábeis cavaleiros, o que permite associá-los à figura valente e altaneira do gaúcho, em permanente 
contato e luta com a natureza. O recorte nesse caso se faz via cavalo, elemento emblemático do gaúcho. (OLIVEN, 1992, p. 12).

Ainda em correlação à afeição do homem gaúcho com a natureza, é possível salientar o amor à terra, no caso o amor ao Estado, como se destaca nestes versos de "Canção de gaúcho": "Gaúcho eu sou/ Nasci feliz/ Nesta terra formosa onde estou/ Sob o céu deste lindo país". Weber (2010) relaciona esse apego ao solo às contribuições indígenas na formação cultural do Rio Grande do Sul ao explicar que "este perfil de associação com a natureza, tão peculiar das populações indígenas, permaneceu na formação da sociedade sul-rio-grandense, fazendo perpetuar o amor pelo solo ao qual se pertence e do qual se tira o sustento" (WEBER, 2010, p. 31-32).

Nessa primeira tendência verificada nas canções, já se percebe que a canção é uma mensagem portadora de significados que servem para orientar em um determinado momento histórico - grupo social ao qual a canção é destinada (MORIGI; BONOTO, 2004). Considerando que as canções de José Cláudio Machado, como a exemplificada nos parágrafos anteriores, são contemporâneas, subentende-se que essa imagem de gaúcho como forte e viril ainda é perpetuada na contemporaneidade. Ou seja, mesmo transcorridos vários anos de busca pela igualdade entre homens e mulheres e busca de uma sociedade menos conservadora, as letras permanecem cultuando a figura masculina como aquela que se restringe à vida campeira, que seria superior à mulher.

Além disso, é possível destacar que, mesmo transcorridos quase cem anos do surgimento do tradicionalismo gaúcho, há, nas canções analisadas todas do final do século $X X$ - uma valorização cultural do passado. Isso fica evidente, por exemplo, no cenário onde estão os homens gaúchos, ou seja, o campo, na descrição de suas atividades, no desejo de ter uma relação afetiva nos moldes conservadores e na ideia de superioridade masculina. Ainda nessa perspectiva existe uma clara naturalização de uma perspectiva patriarcal, conservadora do contexto em que se insere o homem gaúcho, algo que toma maior evidência quando se comparam as representações femininas e masculinas. Enquanto a mulher está à espera de um homem gaúcho, à mercê de sua coragem e virilidade, o homem é dono de seu destino, goza da liberdade e age com coragem para lutar.

Não há atualização quanto à representação da figura masculina, pois esta aparece com os mesmos traços que a definiam no século XVIII tanto no que se refere a valores, culturas, comportamentos e vida cotidiana. Isso remete a uma construção da memória de forma acrítica, dada a ausência de questionamentos sobre o passado e sobre a função da figura masculina naquele contexto distante. Não se alude, por exemplo, ao cenário da cidade e a outras ocupações masculinas, como se o homem continuasse vivendo da mesma forma que nos séculos passados.

Dessa forma, entende-se que as letras das canções analisadas mostram-se não inovadoras: repetem temas, formas, linguagem e valores já conhecidos nos séculos anteriores, sem acompanhar uma perspectiva mais atual de configuração do homemsulino. A partir dessas considerações, constata-se que a memória dessa representação do homem gaúcho, além de cultuar um tradicionalismo conservador, enaltece traços da figura masculina que podem representar uma parcela social, mas sem dúvida não a coletividade.

\section{Referências}

DICIONÁRIO dos símbolos. Cavalo. Disponível em: http://www.dicionariodesimbolos.com.br/cavalo/. Acesso em: 30 jun. 2015.

KONFLANZ, Celso. A moderna tradição gaúcha: Um estudo sociológico sobre o Tradicionalismo Gaúcho. Dissertação (Programa de Pós-Graduação em Ciências Sociais da Faculdade de Filosofia e Ciências Humanas da Pontifícia Universidade Católica do Rio Grande do Sul). Porto Alegre, 2013.

LESSA, Barbosa. O sentido e o valor do tradicionalismo. S.d. Disponível em $<$ http://www.mtg.org.br/historico/240> Acesso em: 20 jul. 2015.

LUVIZOTTO, Caroline Kraus. As tradições gaúchas e sua racionalização na modernidade tardia. São Paulo: Cultura Acadêmica, 2010. Disponível em 
$<$ http://static.scielo.org/scielobooks/cq8kr/pdf/luvizotto -9788579830884. df $>$ Acesso em: 12 jun. 2015.

MACHADO, José Cláudio. Milonga abaixo do mau tempo. (Letra de canção). Album Entre Amigos, 2007.

Canção de Gaúcho. (Letra de canção). Disponível em: http://letras.mus.br/jose-claudiomachado/1179317I. Acesso em: 20 jun. 2015.

São as armas que conheço. (Letra de canção). Disponível em: <http://letras.mus.br/joseclaudio-machado/723819/>. Acesso em: 20 jun. 2015.

MORRIGI, Valdir José; BONOTTO, Martha E. K. A narrativa musical, memória e fonte de informação afetiva. Em questão, Porto Alegre, v.10, n.1, p.143161, jan./jun. 2004.

OLIVEN, Ruben George. A fabricação do gaúcho. Cadernos CERU (2a SÉRIE), n. 1, p. 79-91, 1985. Disponível em: $<$ www.revistas. usp.br/cerusp/article/viewFile/83137/86 173>. Acesso em: 12 jun. 2015.

A polêmica identidade gaúcha. Cadernos de Antropologia no 4, Porto Alegre, p. 12, 1992.

SILVA, Tomaz Tadeu. Documentos de identidade. Uma introdução às teorias do currículo. Belo Horizonte: Autêntica, 2000.

SILVA, Kalina Vanderlei; SILVA, Maciel Henrique. Dicionário de Conceitos Históricos. São Paulo: Contexto, 2006. Disponível em: $<$ www.igtf.rs.gov.br/wpcontent/uploads/.../conceito TRADIC̣ÃO.pdf>. Acesso em: 12 jun. 2015.

WEBER, Eliana. Políticas públicas de fortalecimento cultural do tradicionalismo gaúcho frente à fragmentação do sujeito na globalização. $177 \mathrm{f}$. Dissertação (Mestrado em Direito - Universidade de Santa Cruz do Sul). Santa Cruz do Sul, 2010. Disponível em: $<$ www.unisc.br/portal/images/stories/mestrado/direito/. ..eliana weber.pdf $>$. Acesso em: 12 jul. 2015. 